\title{
Building p53
}

\author{
Tamara Terzian $^{1}$ and Guillermina Lozano ${ }^{2,3}$ \\ ${ }^{1}$ Department of Dermatology/Stem Cell Biology, University of Colorado at Denver, Aurora, Colorado 80045, USA; ${ }^{2}$ Department \\ of Genetics, University of Texas M.D. Anderson Cancer Center, Houston, Texas 77030, USA
}

The intricacies of p53 regulation just got more complex. While much is known about the transcriptional regulation of p53 target genes, Chen and Kastan (pp. 2146-2156) uncovered a new mechanism regarding the making of the p53 protein itself. In the October 1, 2010, issue of Genes \& Development, they introduced us to a novel mechanism of p53 translational control, by which a $5^{\prime}-3^{\prime}$ cap-independent, poly(A)-independent, RNA-RNA interaction enhances p53 translation by binding the ribosomal protein RPL26 following DNA damage. Oligonucleotides designed against this $5^{\prime}-3^{\prime}$ untranslated region (UTR) duplex disrupted the binding of RPL26 to p53 mRNA and reduced p53 synthesis and, therefore, function. This study reveals an alternate mechanism of translational control to regulate p53 levels.

The p53 tumor suppressor is tightly regulated and maintained at low physiological levels in unstressed cells to avoid its deleterious effects on living organisms. Thus, p53 expression is regulated by a variety of means, including transcriptional and translational control, alternative splicing, changes in protein degradation rate or stability, and regulation of subcellular localization (Hollstein and Hainaut 2010). All of this is to ensure that p53 is maintained at low levels, since it is a master regulator of genes involved in important processes such as apoptosis, cell cycle progression, senescence, differentiation, and DNA repair (Levine and Oren 2009; Vousden and Prives 2009). Therefore, deregulation of p53 levels has serious consequences on cell growth and survival (when overexpressed) or confers an increased risk for cancer (haploinsufficiency, for example).

In response to multiple stimuli, including DNA damage, the p53 protein is rapidly stabilized and activated (Horn and Vousden 2007). p53 stabilization is ensured primarily by uncoupling its main negative regulator, the E3 ubiquitin ligase MDM2, which regulates ubiquitination, degradation (Haupt et al. 1997; Honda et al. 1997; Kubbutat et al. 1997), and nuclear export (Toledo and Wahl 2006). Under stress, post-translational modifications of both proteins are induced to disrupt the p53/MDM2 complex, resulting in an increase in p53 half-life and a rise

[Keywords: p53; translational control; DNA damage; cytoprotection] ${ }^{3}$ Corresponding author.

E-MAIL gglozano@mdanderson.org; FAX (713) 834-6380.

Article is online at http://www.genesdev.org/cgi/doi/10.1101/gad.1988510. in cellular protein levels (Meek and Anderson 2009). On the other hand, MDM2 and p53 form an autoregulatory feedback loop where $M D M 2$ is the transcriptional target of p53 (Barak et al. 1993; Wu et al. 1993; Lahav et al. 2004), which also contributes to regulation of p53 levels.

A number of other mechanisms contribute to p53 stabilization in response to different stimuli; translational control of p53 mRNA is one such example. This type of regulation has considerable impact on p53 levels and may be critical for its tumor-suppressive function (Halaby and Yang 2007). Translation occurs in the ribosome, and several proteins govern assembly and processing of mRNAs. The ribosomal protein RPL26 in particular binds to $p 53$ mRNA, increasing its translation. RPL26 also binds to MDM2, and is polyubiquitinated and targeted for proteasomal degradation (Ofir-Rosenfeld et al. 2008). Since the binding of RPL26 to MDM2 diminishes its availability for interaction with p53 mRNA, p53 translation and activity are reduced under normal physiological conditions (OfirRosenfeld et al. 2008). When stressed, MDM2 is subjected to post-translational modification that is proposed to render it less efficient at disrupting RPL26-p53 mRNA binding, leading to up-regulation of p53 translation (Takagi et al. 2005; Ofir-Rosenfeld et al. 2008). Takagi et al. (2005) demonstrated that optimal p53 induction after DNA damage calls for a robust increase in p53 mRNA translation and efficient binding of RPL2 6 to the $5^{\prime}$ untranslated region (UTR) of p53 mRNA. Thus, RPL26 is a bona fide positive regulator of $\mathrm{p} 53$. While RPL26 overexpression directly increased p53 translation, cellular levels, and subsequent functions (G1 arrest and apoptosis), RPL26 knockdown with siRNAs attenuated p53 translation and weakened its apoptotic response to DNA damage (Takagi et al. 2005). Another protein, nucleolin, competes with RPL2 6 for binding to the $5^{\prime}$ UTR of $p 53$ mRNA to influence translation. Its overexpression has the opposite effect of diminishing p53 protein levels and inhibiting the ionizing radiation (IR)-induced increase in p53 translation and induction. Moreover, inhibition of nucleolin enhanced p53 translation (Takagi et al. 2005). These proteins and others that bind to the $5^{\prime}$ and $3^{\prime}$ UTR of $p 53$, controlling its translation in response to stress, effectively alter wild-type and, likely, mutant p53 cellular levels and functions. Higher levels of p53 will eliminate damaged cells and ensure exclusive survival of intact cells in the face of a general translational decrease. Thus, translational control of p53 in stressed cells is critical. 
The Kastan group (Takagi et al. 2005) demonstrated previously the pivotal role the 5' UTR of p53 mRNA plays in DNA damage-induced translational control.

Yet another layer of complexity of p53 regulation is presented by Chen and Kastan (2010), and shows a novel model of DNA damage-induced translational control that modulates p53 synthesis and activity. Chen and Kastan (2010) show an RPL26-dependent, cap-independent, and poly(A)-independent RNA base-pairing interaction between the $5^{\prime}$ and $3^{\prime}$ UTR sequences induced by DNA damage that is required for optimal p53 mRNA translation (Fig. 1). Disrupting mutations (as few as 3 nucleotides) in this predicted dsRNA region interrupted the binding of RPL2 6 to human p53 mRNA and decreased its induction. These mutations occur in the last 3 base pairs of the 5'-3' UTR-interacting region. Functional reporter expression assays as well as elegantly designed experiments based on creating compensatory mutations that restored complementarity of this UTR interaction demonstrated the importance of the 3' UTR p53 region and the dependence of RPL26 on the dsRNA sequence for optimal binding to $p 53$ mRNA, and its positive translational regulation induced by DNA damage.

While alterations of many ribosomal proteins are capable of inducing a change in p53 protein levels, RPL26 is uniquely involved in p53 translation. Since the increase in binding to p53 mRNA after DNA damage occurs in the nucleus, the findings of Chen and Kastan (2010) shed light on an extraribosomal function of RPL26 that selectively targets p53 activation. Exactly how RPL26 binds to p53 remains to be elucidated.

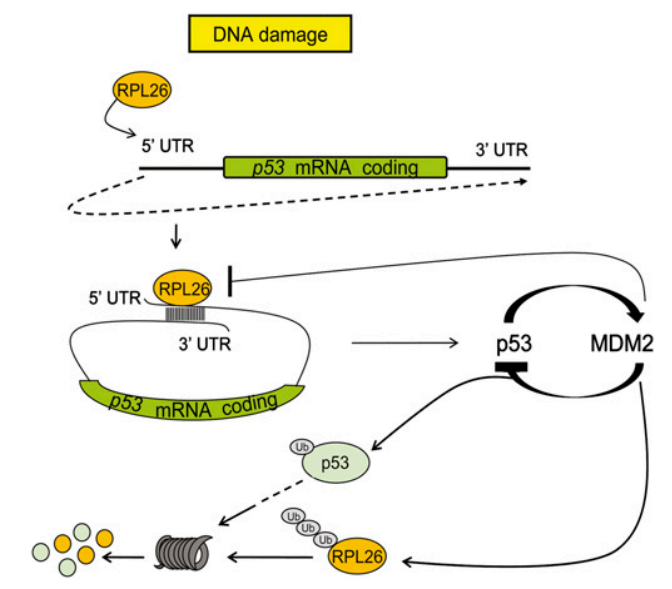

Figure 1. Schematic representation of DNA damage-induced translational regulation of $p 53$ by RPL26. DNA damage promotes the binding of ribosomal protein RPL26 to a double-stranded UTR of $p 53$ mRNA. This region is made from the base-pairing of $5^{\prime}$ and $3^{\prime}$ UTR of p53 mRNA, resulting in its circularization. RPL26 binding to p53 is required for optimal p53 translation. MDM2 keeps p53 protein levels in check and physiologically low by inhibiting its activity, monoubiquitinating and targeting it for degradation by the proteasome. MDM2 also binds to RPL26, polyubiquitinates it, and promotes its degradation. Furthermore, MDM2 disrupts the binding of RPL26 to $p 53$ mRNA. Thus, RPL26 exhibits positive effects on $\mathrm{p} 53$ activity.
Commonly, mRNA-specific translational regulation is determined by protein complexes that recognize particular regulatory sequences or structural features that are present mainly in the $5^{\prime}$ and/or 3' UTRs (Standart and Jackson 1994; Gebauer and Hentze 2004). These regions are generally relatively conserved, which highlights their functional importance with a more recognized role of the 5' UTR in translational modulation and the $3^{\prime}$ UTR in RNA stability. Their importance in p53 mRNA translation has also been established (Mosner et al. 1995; Fu and Benchimol 1997; Mazan-Mamczarz et al. 2003; Schumacher et al. 2005). However, the discovery by Chen and Kastan (2010) of this 5'-3' UTR RNA-RNA basepairing phenomenon-rather than through protein mediated, cap-poly(A) bridging and circularization of the mRNA-represents an original and intriguing regulatory mechanism for p53 translation (Fig. 1). While this type of cap-independent $5^{\prime}-3^{\prime}$ UTR communication is uncommon in eukaryotic cells, it is a known mechanism in viruses (such as viruses in the Luteoviridae and Tombusviridae families) (Fabian and White 2004; Miller and White 2006) and bacteria (Franch et al. 1997). In viruses, the RNA forms a closed loop through direct long-range RNA-RNA communication between the 5' and 3' UTR ends of mRNA. This mRNA circle brings the $3^{\prime}$ UTR end in close proximity to the $5^{\prime}$ UTR, where the $3^{\prime}$ UTR regulatory factors that control the initiation of translation reside (Gebauer and Hentze 2004; Miller and White 2006). In some cases, this bridging seems to play a role in viral RNA replication, with no obvious impact on translation (Villordo and Gamarnik 2009). In other viral examples, such as the Barley yellow dwarf (Guo et al. 2001; Miller and White 2006) and Tomato bushy stunt viruses [both lack the $5^{\prime}$ cap and $3^{\prime}$ poly(A)] (Fabian and White 2004; Miller and White 2006), this mechanism regulates translation. Similar 5'-3' RNA bridging was observed in multiple viral RNAs, and could represent a widespread strategy for viral RNA replication but not translation (Filomatori et al. 2006). Over and above the significance of the findings of Chen and Kastan (2010) regarding the regulation of p53 protein levels and the consequent therapeutic implications, the mechanism of 5'-3' UTR base-pairing that increases the efficiency of mRNA translation will be viewed with much interest by those studying rapid environmental response genes, not only in viruses and bacteria, but especially in eukaryotic cellular systems.

Chen and Kastan (2010) also highlighted the need for therapeutic agents that limit the physiological effects of p53 activation after DNA damage by transiently limiting the transactivation capacity of p53. In cases of accidental exposure to radiation, therapeutic irradiation, or other stresses (such as hypoxia induced by heart attack or stroke) that may result in p53-mediated cytotoxicity, a means of modulating the $\mathrm{p} 53$ response will be a valuable clinical tool in enhancing survival and limiting tissue damage. To this end, Chen and Kastan (2010) designed and synthesized small single-stranded oligonucleotides that cover the crucial sequences of the $5^{\prime}-3^{\prime}$ RNA basepairing area. Cell culture experiments were used to 
successfully demonstrate that these synthetic oligonucleotides were able to limit p53 translation by blocking RPL26 binding to $p 53$ mRNA (without completely inhibiting p53 induction), thereby restraining the p53 response to diverse types of DNA damage and stresses without affecting p53 mRNA levels. It is important to keep in mind, however, that the same $5^{\prime}$ and $3^{\prime}$ sequences are present in mutant p53 mRNA, and that missense mutations in p53 commonly observed in human tumors manifest gain-of-function phenotypes (Brosh and Rotter 2009). This is in agreement with the fact that mouse models of a $p 53^{R 172 H}$ knock-in allele with increased mutant p53 protein levels may present with accelerated tumor progression and increased metastasis (Lang et al. 2004; Olive et al. 2004; Terzian et al. 2008). We hypothesize that therapeutic strategies that reduce protein levels of mutant p53 may limit tumor progression and/or metastasis. On the other hand, while the possibilities offered by therapeutic interruption of $5^{\prime}-3^{\prime}$ UTR base pair-enhanced p53 translation are intriguing, it is unclear whether this may be a more or less effective strategy than a conventional siRNA-mediated approach to $p 53$ silencing. Moreover, the most likely roadblock to the future clinical use of oligonucleotide-based therapeutic strategies remains the success of the delivery systems currently under development.

Finally, this original finding will set the stage for a plethora of clinical and therapeutic strategies in disease and cancer. This novel p53 translational regulation is definitely one area that we "guessed or thought of" that will need to be studied further and "will become clear and obvious over the next decade" (Levine and Oren 2009). Since p53 is important in maintaining tissue homeostasis and cancer prevention, mastering the fine tuning of its production will be a challenge and will serve as an example in studies of other crucial proteins. The ability to modulate p53 protein levels in specific settings or under certain forms of stress using these types of oligonucleotides should have minimal risk for secondary cancers. Furthermore, testing this approach in vivo on mouse or other models will permit the validation of this tool as a valuable addition to our arsenal of therapies against deleterious effects of high p53 levels.

\section{Acknowledgments}

We thank Allen Miller and Jeffrey Kieft for advice and helpful discussions.

\section{References}

Barak Y, Juven T, Haffner R, Oren M. 1993. mdm2 expression is induced by wild type p53 activity. EMBO J 12: 461-468.

Brosh R, Rotter V. 2009. When mutants gain new powers: News from the mutant p53 field. Nat Rev Cancer 9: 701-713.

Chen J, Kastan MB. 2010. 5'-3'-UTR interactions regulate p53 mRNA translation and provide a target for modulating p53 induction after DNA damage. Genes Dev 24: 2146-2156.

Fabian MR, White KA. 2004. 5'-3' RNA-RNA interaction facilitates cap- and poly(A) tail-independent translation of tomato bushy stunt virus mrna: A potential common mechanism for tombusviridae. J Biol Chem 279: 28862-28872.
Filomatori CV, Lodeiro MF, Alvarez DE, Samsa MM, Pietrasanta L, Gamarnik AV. 2006. A 5' RNA element promotes dengue virus RNA synthesis on a circular genome. Genes Dev 20: 2238-2249.

Franch T, Gultyaev AP, Gerdes K. 1997. Programmed cell death by hok/sok of plasmid R1: Processing at the hok mRNA 3 '-end triggers structural rearrangements that allow translation and antisense RNA binding. I Mol Biol 273: 38-51.

Fu L, Benchimol S. 1997. Participation of the human p53 3'UTR in translational repression and activation following $\gamma$-irradiation. $E M B O J$ 16: 4117-4125.

Gebauer F, Hentze MW. 2004. Molecular mechanisms of translational control. Nat Rev Mol Cell Biol 5: 827-835.

Guo L, Allen EM, Miller WA. 2001. Base-pairing between untranslated regions facilitates translation of uncapped, nonpolyadenylated viral RNA. Mol Cell 7: 1103-1109.

Halaby MJ, Yang DQ. 2007. p53 translational control: A new facet of p53 regulation and its implication for tumorigenesis and cancer therapeutics. Gene 395: 1-7.

Haupt Y, Maya R, Kazaz A, Oren M. 1997. Mdm2 promotes the rapid degradation of p53. Nature 387: 296-299.

Hollstein M, Hainaut P. 2010. Massively regulated genes: The example of TP53. J Pathol 220: 164-173.

Honda R, Tanaka H, Yasuda H. 1997. Oncoprotein MDM2 is a ubiquitin ligase E3 for tumor suppressor p53. FEBS Lett 420: $25-27$.

Horn HF, Vousden KH. 2007. Coping with stress: Multiple ways to activate p53. Oncogene 26: 1306-1316.

Kubbutat MH, Jones SN, Vousden KH. 1997. Regulation of p53 stability by Mdm2. Nature 387: 299-303.

Lahav G, Rosenfeld N, Sigal A, Geva-Zatorsky N, Levine AJ, Elowitz MB, Alon U. 2004. Dynamics of the p53-Mdm2 feedback loop in individual cells. Nat Genet 36: 147-150.

Lang GA, Iwakuma T, Suh YA, Liu G, Rao VA, Parant JM, Valentin-Vega YA, Terzian T, Caldwell LC, Strong LC, et al. 2004. Gain of function of a p53 hot spot mutation in a mouse model of Li-Fraumeni syndrome. Cell 119: 861-872.

Levine AJ, Oren M. 2009. The first 30 years of p53: Growing ever more complex. Nat Rev Cancer 9: 749-758.

Mazan-Mamczarz K, Galban S, Lopez de Silanes I, Martindale JL, Atasoy U, Keene JD, Gorospe M. 2003. RNA-binding protein HuR enhances p53 translation in response to ultraviolet light irradiation. Proc Natl Acad Sci 100: 8354-8359.

Meek DW, Anderson CW. 2009. Posttranslational modification of p53: Cooperative integrators of function. Cold Spring Harb Perspect Biol 1: a000950. doi: 10.1101/cshperspect. a000950.

Miller WA, White KA. 2006. Long-distance RNA-RNA interactions in plant virus gene expression and replication. Annu Rev Phytopathol 44: 447-467.

Mosner J, Mummenbrauer T, Bauer C, Sczakiel G, Grosse F, Deppert W. 1995. Negative feedback regulation of wild-type p53 biosynthesis. EMBO J 14: 4442-4449.

Ofir-Rosenfeld Y, Boggs K, Michael D, Kastan MB, Oren M. 2008. Mdm2 regulates p53 mRNA translation through inhibitory interactions with ribosomal protein L26. Mol Cell 32: $180-189$.

Olive KP, Tuveson DA, Ruhe ZC, Yin B, Willis NA, Bronson RT, Crowley D, Jacks T. 2004. Mutant p53 gain of function in two mouse models of Li-Fraumeni syndrome. Cell 119: 847-860.

Schumacher B, Hanazawa M, Lee MH, Nayak S, Volkmann K, Hofmann ER, Hengartner M, Schedl T, Gartner A. 2005. Translational repression of $C$. elegans 553 by GLD-1 regulates DNA damage-induced apoptosis. Cell 120: 357-368.

Standart N, Jackson RJ. 1994. Regulation of translation by specific protein/mRNA interactions. Biochimie 76: 867-879. 
Terzian and Lozano

Takagi M, Absalon MJ, McLure KG, Kastan MB. 2005. Regulation of p53 translation and induction after DNA damage by ribosomal protein L26 and nucleolin. Cell 123: 49-63.

Terzian T, Suh YA, Iwakuma T, Post SM, Neumann M, Lang GA, Van Pelt CS, Lozano G. 2008. The inherent instability of mutant p53 is alleviated by Mdm2 or p16INK4a loss. Genes Dev 22: 1337-1344.

Toledo F, Wahl GM. 2006. Regulating the p53 pathway: In vitro hypotheses, in vivo veritas. Nat Rev Cancer 6: 909-923.

Villordo SM, Gamarnik AV. 2009. Genome cyclization as strategy for flavivirus RNA replication. Virus Res 139: 230-239.

Vousden KH, Prives C. 2009. Blinded by the light: The growing complexity of p53. Cell 137: 413-431.

Wu X, Bayle JH, Olson D, Levine AJ. 1993. The p53-mdm-2 autoregulatory feedback loop. Genes Dev 7: 1126-1132. 


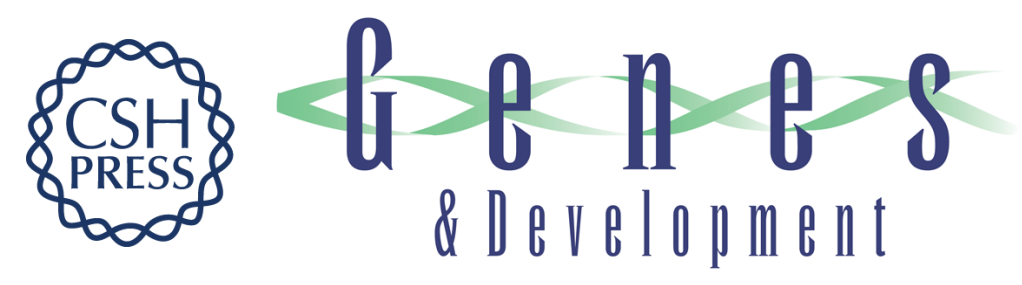

\section{Building p53}

Tamara Terzian and Guillermina Lozano

Genes Dev. 2010, 24:

Access the most recent version at doi:10.1101/gad.1988510

\section{Related Content \\ 5232-UTR interactions regulate p53 mRNA translation and provide a target for modulating p53 induction after DNA damage Jing Chen and Michael B. Kastan \\ Genes Dev. October, 2010 24:2146-2156 \\ References This article cites 32 articles, 8 of which can be accessed free at: \\ http://genesdev.cshlp.org/content/24/20/2229.full.html\#ref-list-1 \\ Articles cited in: \\ http://genesdev.cshlp.org/content/24/20/2229.full.html\#related-urls \\ License \\ Email Alerting \\ Receive free email alerts when new articles cite this article - sign up in the box at the top \\ Service right corner of the article or click here.}

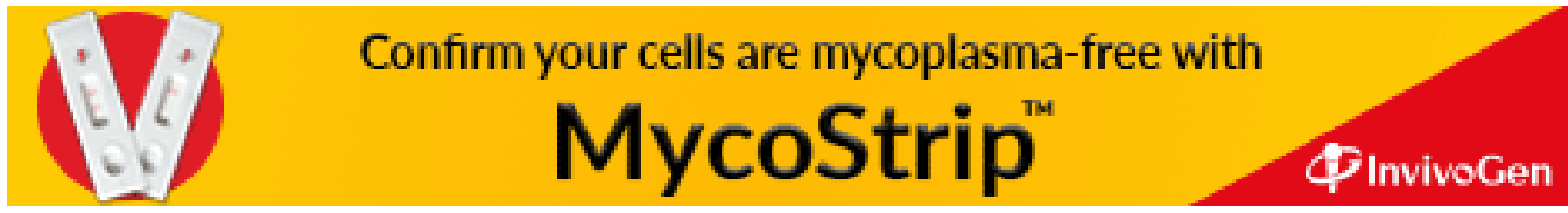

